\title{
Detection of ferromagnetic objects in local magnetic anomaly of the Baltic Sea
}

\author{
Mirosław Wołoszyn, Ph. D. \\ Gdansk University of Technology
}

ABSTRACT

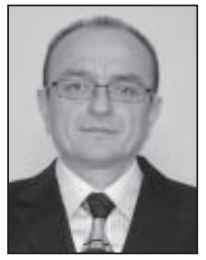

In geological researches several kinds of methods are applied to discovering the natural resources. Planes, helicopters and UAVs (UnmAnned Vehicle) are used in researches in large areas. The gravity, electromagnetic and magnetic methods, which are used in geological researches, are presented in this paper. The special attention was paid to magnetic systems installed on mobile platforms. The magnetic field of the Earth obtained from mathematical model was compared to the real magnetic field in the selected part of the Baltic Sea. The results of the calculations showed that the mathematical model of the Earth's magnetic field does not consider local magnetic anomalies. The strong local magnetic anomalies cause serious problems with detection of underwater objects. Special problems appear in the magnetic system on a helicopter, which are presented in this paper.

Keywords: geological researches, gravity, electromagnetic, magnetic methods

\section{INTRODUCTION}

In geological researches several kinds of methods are applied to discovering the natural resources. Planes, helicopters and UAVs (UnmAnned Vehicle) are used in researches in large areas. The gravity, electromagnetic and magnetic methods are applied to researches. In the gravity method the extremely small changes of the Earth's gravity are measured [1]. The sensitivity of contemporary gravimeters is less then $1 \mathrm{mGal}$ $\left(1 \mathrm{Gal}=10^{-2} \mathrm{~m} / \mathrm{s}^{2}\right)$. The gravimeters allow to measure the changes of the Earth's gravity on level close to $10^{-6} \mathrm{~g}$. One of a few leading producers of extremely sensitive gravimeters is Gravimetric Technologies Ltd. a company in Moscow [2]. The GT-1A gravimeter installed on the Cessna 404 plane was shown in fig.1 [3].

Deposits of natural resources are discovered also by applying the electromagnetic method. The first electromagnetic systems appeared and were developed in Scandinavia, the USA and Canada in the 20s of XX century. The electromagnetic method is applied to measure the conductivity of the soil. The electromagnetic systems are installed on planes or helicopters. A big coil is towed by a helicopter or carried by a plane. The current impulse in the coil generates strong magnetic field (primary field), which penetrates layers of the Earth (fig. 2). The time-varying field produces eddy currents in the soil. After the switch off of the current in the coil they are only the eddy currents that produce the magnetic field (secondary

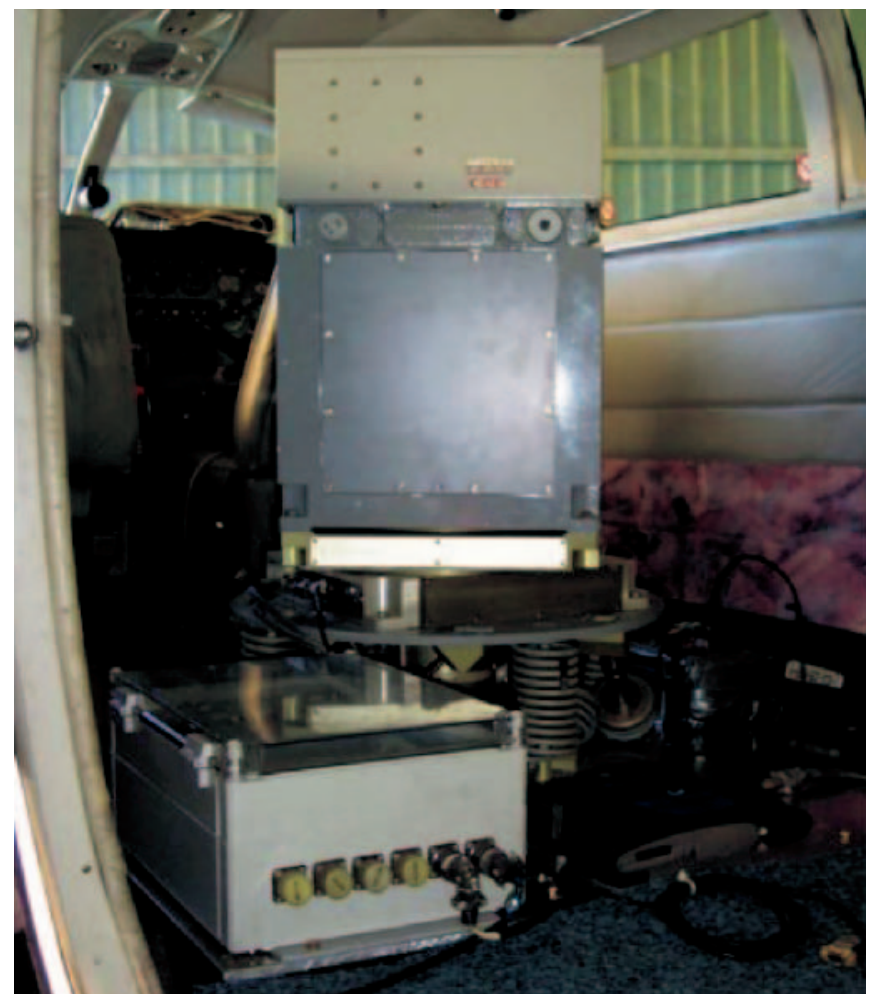

Fig. 1. The GT-1A gravimeter installed on Cessna 404 plane [12] 
field). The time-varying secondary field produces emf voltage in the measure coil. The induced emf voltage depends on a conductivity of the soil. The analysis of the conductivity of the ground allows to detect natural resources.

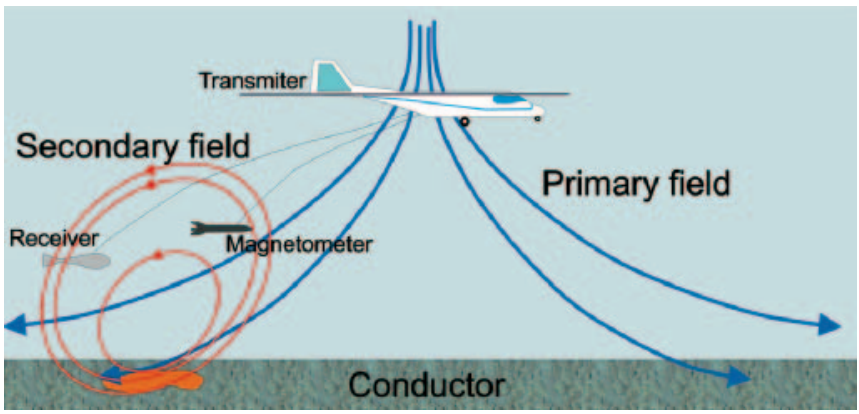

Fig. 2. The electromagnetic method

One of the biggest commercial companies (Fugro) has three electromagnetic systems for geological researches: GEOTEM (fig. 3), MEGATEM and TEMPEST. The biggest MEGATEM system is installed on Dash 7 plane and allows to discover the natural resources up to $300 \mathrm{~m}$. The value of the magnetic moment generated by the system is $2.2 \cdot 10^{6} \mathrm{Am}^{2}$.

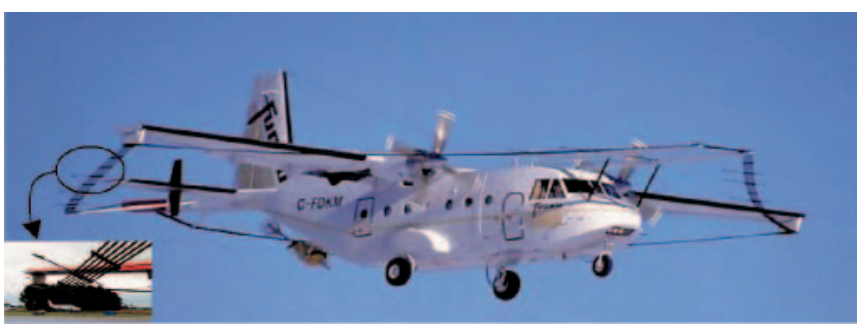

Fig. 3. The GEOTEM electromagnetic system on the plane Casa 212 [4]

The magnetic method is also applied to geological researches. Homogeneity of the Earth's magnetic field is disturbed by different properties of the Earth's layers. This method is also applied to detection of ferromagnetic objects (UXO - UneXploded Objects, submarines, wrecks, landmines and marine mines). Each ferromagnetic object disturbs the homogeneity of the Earth's magnetic field (fig. 4). The measures of the magnetic field near the object allow to detect, to localize and to identify it [5].

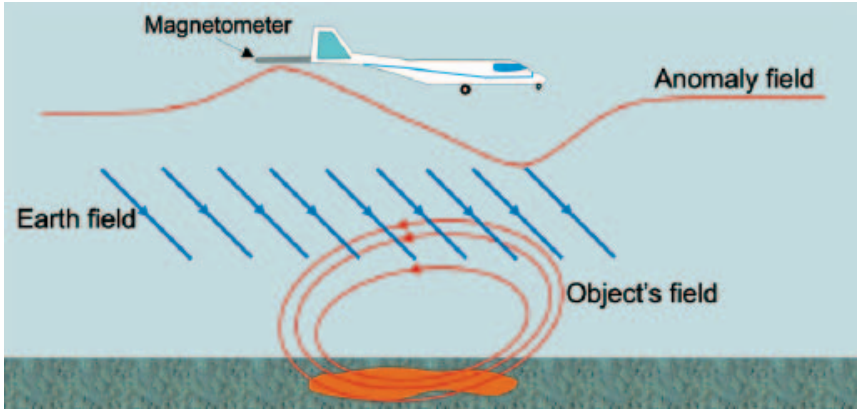

Fig. 4. The disturbance of the homogeneity of the Earth's magnetic field near the ferromagnetic object

The influence of the strong local magnetic anomaly on the magnetic measurements, with systems installed on planes and helicopters, was presented in this paper. The mathematical model of the Earth's magnetic field was described. The magnetic field based on the mathematical model was compared to the real magnetic field of the Baltic Sea. The calculations of the magnetic field were carried out in MathCad [6].

\section{EARTH MAGNETIC FIELD- MATHEMATICAL MODEL}

The magnetic field of the Earth can be described by magnetic scalar potential if $\mathbf{j}=0$ :

$$
\mathbf{H}=-\nabla \Psi
$$

The magnetic flux density over the surface of the Earth is $\mathbf{B}=\mu_{0} \mathbf{H}$. So the equation:

$$
\nabla \mathbf{B}=0
$$

comes down to the form:

$$
\nabla \mathbf{H}=0
$$

On the basis of the equations (2) and (3) the magnetic scalar potential $\Psi$ satisfies the Laplace's equation:

$$
\nabla^{2} \Psi=0
$$

The Laplace's equation in spherical coordinate system is:

$$
\begin{gathered}
\frac{1}{\mathrm{r}^{2}} \frac{\partial}{\partial \mathrm{r}}\left(\mathrm{r}^{2} \frac{\partial \Psi}{\partial \mathrm{r}}\right)+\frac{1}{\mathrm{r}^{2} \sin \theta} \frac{\partial}{\partial \theta}\left(\sin \theta \frac{\partial \Psi}{\partial \theta}\right)+ \\
+\frac{1}{\mathrm{r}^{2} \sin ^{2} \theta} \frac{\partial^{2} \Psi}{\partial \phi^{2}}=0
\end{gathered}
$$

The solution of the Laplace's equation (5) is [7]:

$$
\Psi(\mathrm{r}, \theta, \phi)=\sum_{\mathrm{l}=0}^{\infty} \sum_{\mathrm{m}=0}^{\mathrm{l}}\left(\mathrm{A}_{\mathrm{lm}} \mathrm{r}^{1}+\mathrm{B}_{\mathrm{lm}} \mathrm{r}^{-(1+1)}\right) \mathrm{Y}_{1}^{\mathrm{m}}(\theta, \phi)
$$

where: $\mathrm{A}_{\mathrm{lm}}$ and $\mathrm{B}_{\mathrm{lm}}-$ constants and

$$
\mathrm{Y}_{1}^{\mathrm{m}}(\theta, \phi)=\left[\frac{(21+1)(1-\mathrm{m}) !}{4 \pi(1+\mathrm{m}) !}\right]^{\frac{1}{2}} \mathrm{P}_{1, \mathrm{~m}}(\cos \theta) \mathrm{e}^{\mathrm{jm} \phi}
$$

where: $\mathrm{P}_{1, \mathrm{~m}}-$ Legendre polynomials [7].

Schmidt developed the formulae describing the magnetic scalar potential in 1939 [7]. These formulae allow to calculate the approximate value of the components of the magnetic flux density at any point of the Earth. The magnetic scalar potential of the Earth is:

$$
\begin{gathered}
\Psi(\mathrm{r}, \theta, \phi)= \\
=\frac{\mathrm{a}}{\mu_{0}} \sum_{\mathrm{l}=1}^{\infty} \sum_{\mathrm{m}=0}^{1} \mathrm{P}_{1}^{\mathrm{m}}(\cos \theta)\left(\mathrm{g}_{1}^{\mathrm{m}} \cos \mathrm{m} \phi+\mathrm{h}_{1}^{\mathrm{m}} \sin \mathrm{m} \phi\right)
\end{gathered}
$$

where: $\mathrm{P}_{1}^{\mathrm{m}}$ - partially normalized Schmidt's functions [7].

The Gauss' coefficients $\left(\mathrm{g}_{1}^{\mathrm{m}}\right.$ and $\left.\mathrm{h}_{1}^{\mathrm{m}}\right)(8)$ are obtained by using many sets of observations of the components of the magnetic field at many points of the Earth. The components of the magnetic flux density of the Earth are (for $\mathbf{1}_{x}=-\mathbf{1}_{\theta}$, $\left.\mathbf{1}_{\mathrm{y}}=\mathbf{1}_{\varphi}, \mathbf{1}_{\mathrm{z}}=-\mathbf{1}_{\mathrm{r}}\right)$ :

$$
\begin{gathered}
\mathrm{B}_{\mathrm{xe}}=\frac{1}{\mathrm{r}} \frac{\partial \psi}{\partial \theta} \\
\mathrm{B}_{\mathrm{ye}}=-\frac{1}{\mathrm{r} \sin \theta} \frac{\partial \psi}{\partial \phi} \\
\mathrm{B}_{\mathrm{ze}}=\frac{\partial \psi}{\partial \mathrm{r}}
\end{gathered}
$$

The modulus of the magnetic flux density in the Cartesian coordinate system is (fig. 5): 


$$
\mathrm{B}_{\mathrm{e}}=\sqrt{\mathrm{B}_{\mathrm{xe}}^{2}+\mathrm{B}_{\mathrm{ye}}^{2}+\mathrm{B}_{\mathrm{ze}}^{2}}
$$

The magnetic inclination is:

$$
\mathrm{I}=\operatorname{arctg}\left(\frac{\mathrm{B}_{\mathrm{ze}}}{\sqrt{\mathrm{B}_{\mathrm{xe}}^{2}+\mathrm{B}_{\mathrm{ye}}^{2}}}\right)
$$

and declination:

$$
\mathrm{D}=\operatorname{arctg}\left(\frac{\mathrm{B}_{\mathrm{ye}}}{\mathrm{B}_{\mathrm{xe}}}\right)
$$

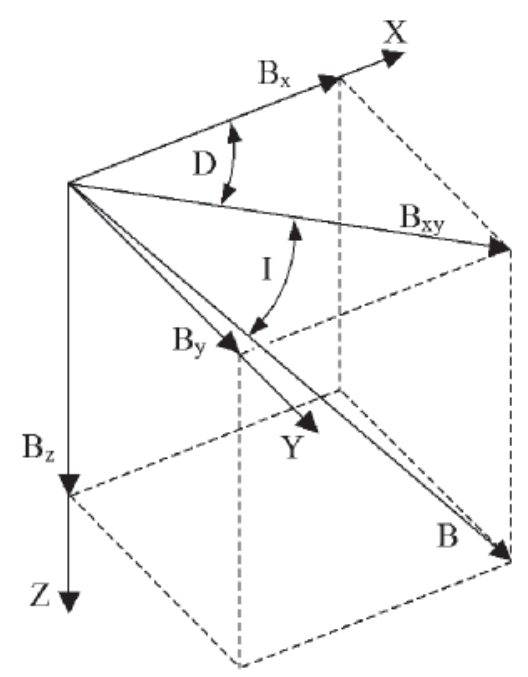

Fig. 5. The components of the Earth's magnetic field

The characteristic components of the Earth's magnetic field were calculated in MathCad for 4-th degree of Gauss coefficients $(1=4)$. The isodynamic chart of the total magnetic flux density was shown in fig. 6 . The isoclinic chart of the inclination in degrees was shown in fig. 7.

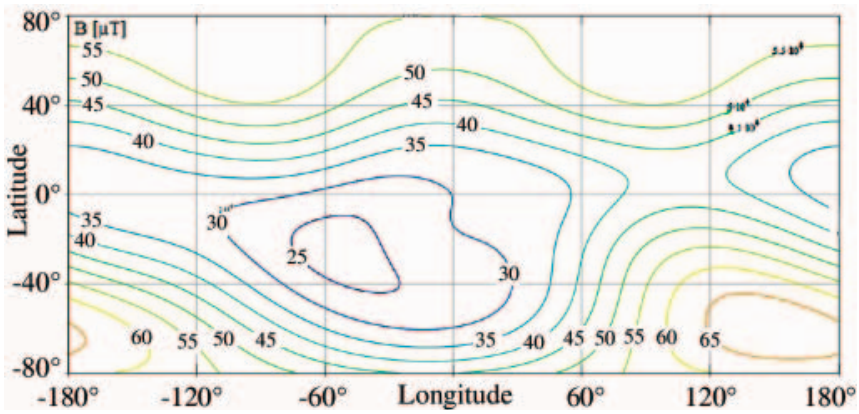

Fig. 6. The isodynamic chart of the total magnetic flux density

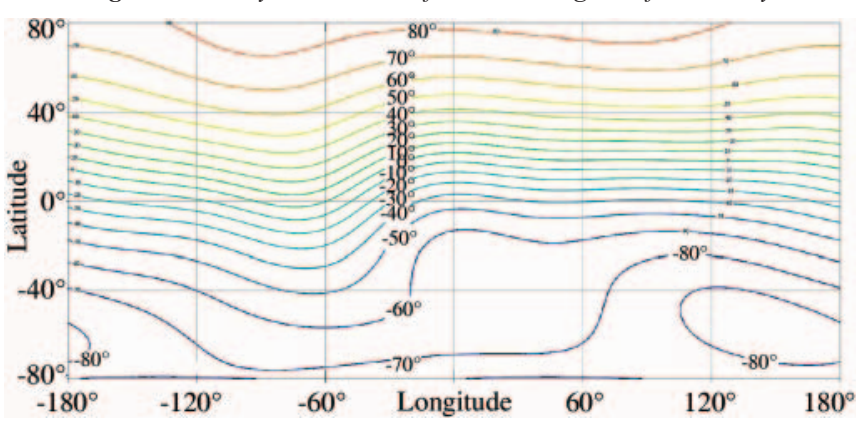

Fig. 7. The isoclinic chart of the inclination in degrees

The distribution of the Earth's magnetic field given by the mathematical model can be used for example in demagnetisation systems of war ships. This distribution has global character and does not include local magnetic anomaly. It is the consequence of the limited number of observatories at which the components of the magnetic field are measured. The distributions of the local magnetic anomalies are different and depend on "geological history" of the Earth's layers. The most popular magnetic anomalies in the world occur in the surroundings of Kursk. The massive layers of rocks containing the iron ore cause these anomalies. The values of the anomalies are about $27 \mathrm{nT} 350 \mathrm{~km}$ over the Earth's surface. The relatively strong local anomalies occur above the Baltic Sea. The distribution of the modulus of the magnetic flux density obtained from mathematical model (8-12) of the Baltic Sea area was shown in fig. 8. The distribution of the magnetic field is approximately linear. The real distribution of the magnetic field in the same area of the Baltic Sea was shown in fig. 9.

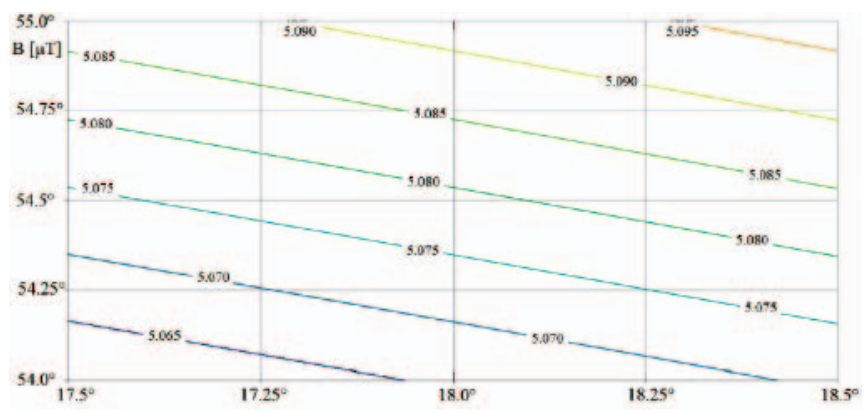

Fig. 8. The isodynamic chart of the total magnetic flux density of the Baltic Sea area

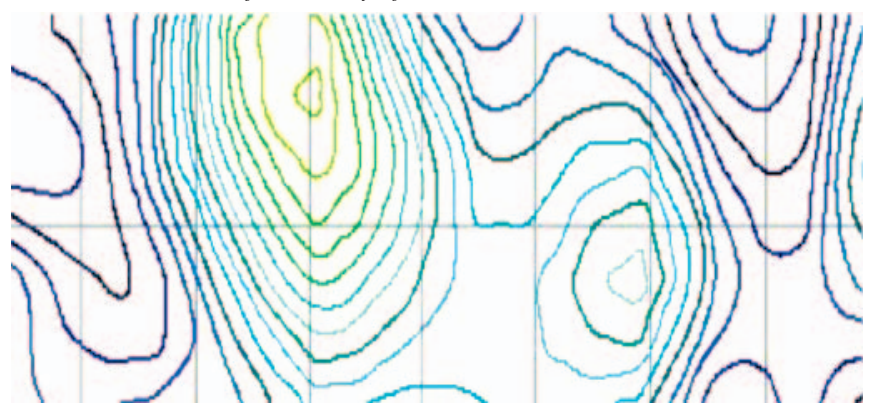

Fig. 9. The real isodynamic chart of the total magnetic flux density of the Baltic Sea area (the same area as in fig.8)

The variations of the magnetic field over the surface of the Baltic Sea are about $2 \mu \mathrm{T}$ an area of several square kilometres. Such strong anomalies make serious problem in detection of ferromagnetic objects.

\section{MAGNETOMETERS}

The scalar magnetometers are used mainly in geological researches and military magnetic systems. The contemporary optically pumped magnetometers are of high sensitivity $10^{-12} \mathrm{~T}$ [8] (fig. 10). The SQUID vector magnetometers of the highest sensitivity (about $10^{-14} \mathrm{~T}$ ) are also used $[8,9]$. The magnetic field of the Earth is about $5 \cdot 10^{-6} \mathrm{~T}$ (fig. 6). So, the sensitivity of the magnetometers is more than million fold less than the total magnetic field of the Earth. The magnetometers are installed on mobile platforms: planes, helicopters or UAV.

\section{MAGNETIC SYSTEMS ON AIR PLATFORMS}

The magnetic system installed on a plane has one or a set of magnetometers. The system with one magnetometer measures the total magnetic field (fig.11).

On account of the natural magnetic variations (hundreds $\mathrm{pT} \div$ several $\mathrm{nT}$ ) the second magnetometer on the ground is 


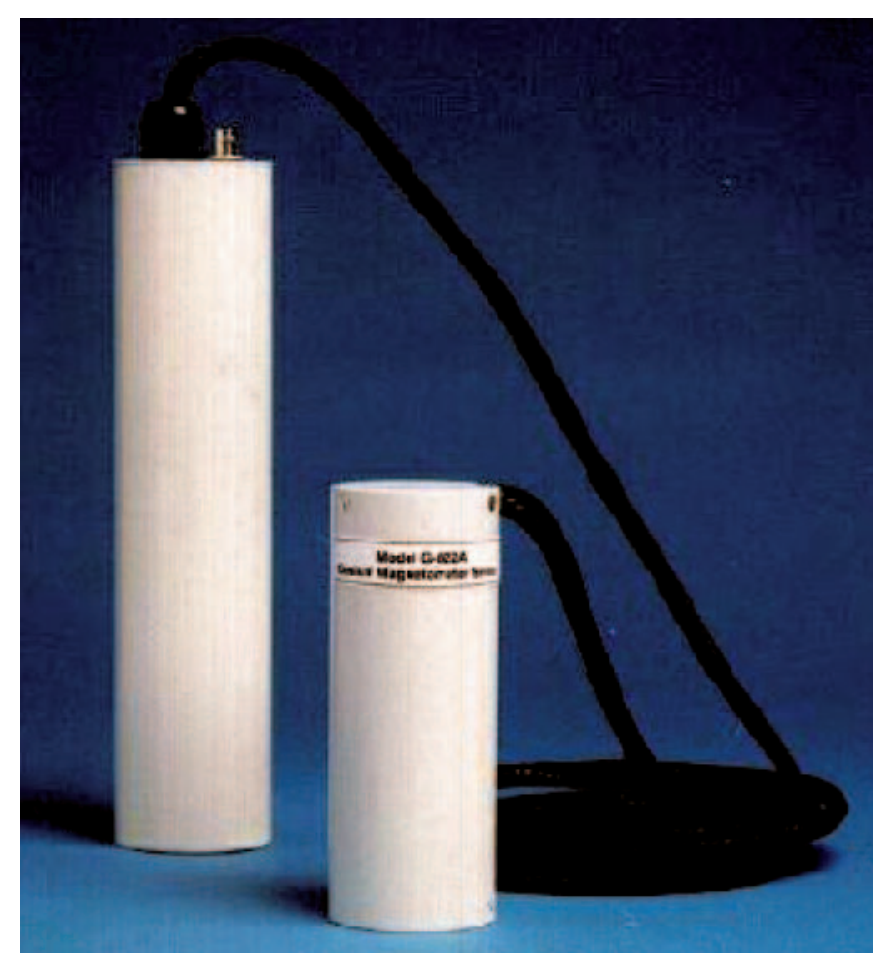

Fig. 10. The optically pumped magnetometer $G-822 \mathrm{~A}$ of Geometrics Company [13]

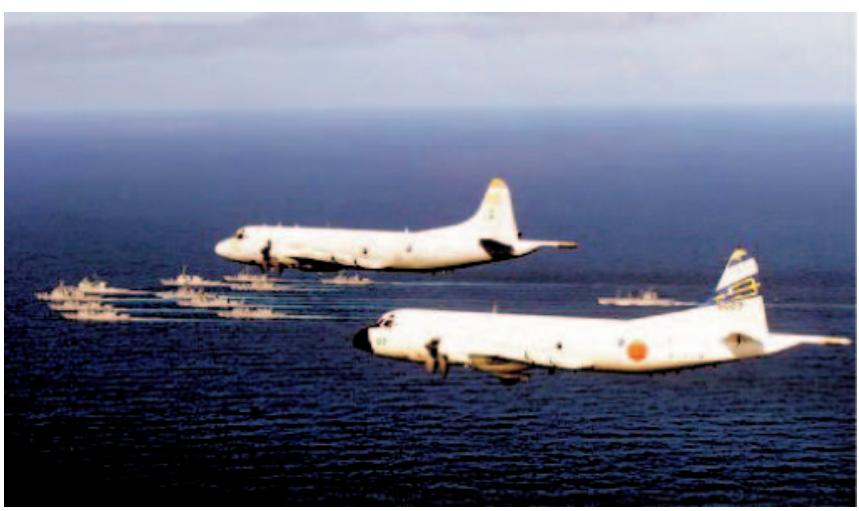

Fig. 11. The military magnetic system with one magnetometer (the sensor is in the tail of the plane)

used as the reference magnetometer. The system with a set of magnetometers measures the difference of modulus of the magnetic field [fig.12].

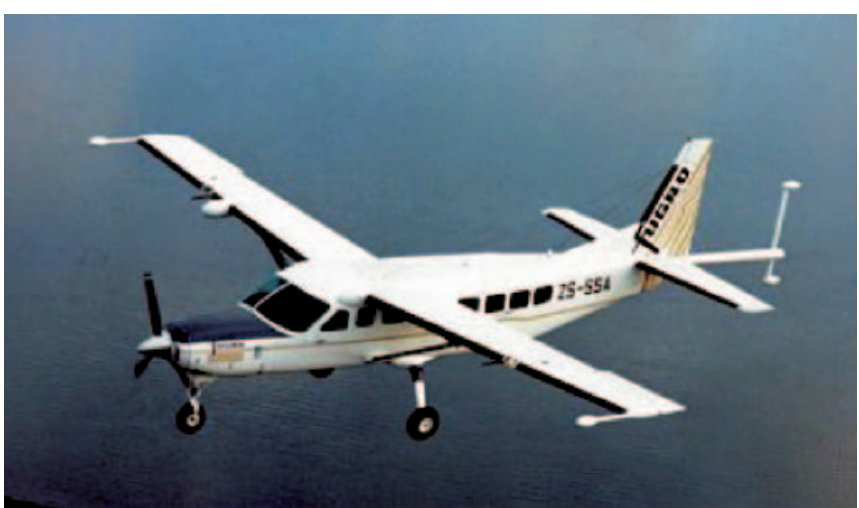

Fig. 12. The magnetic system with a set of magnetometers (the sensors are installed in the tail of the plane and on wings) [14]

The magnetic system on the plane includes the digital compensator of magnetic disturbances $[10,11]$. Each change of the position of the plane in respect of the vector of magnetic field of the Earth disturbs the magnetic field surrounding the plane. These disturbances are caused by constant and induced magnetization of the ferromagnetic elements of the plane and eddy currents induced in the metallic elements of the plane. The mathematical model of the magnetic disturbances is used in the compensator [10]. The linear model is described by the equation:

$$
\mathrm{H}_{\mathrm{T}}(\mathrm{t})=\sum_{\mathrm{i}=1}^{18} \mathrm{k}_{\mathrm{i}} \cdot \mathrm{A}_{\mathrm{i}}(\mathrm{t})
$$

where:

$\mathrm{k}_{\mathrm{i}} \quad$ - the constant factors of the model

$\mathrm{A}_{\mathrm{i}}(\mathrm{t})$ - the functions depend on the position of the plane $\mathrm{t}-$ time.

The values of the functions $\mathrm{A}_{\mathrm{i}}(\mathrm{t})$ are calculated on the basis of the direction cosines and the derivatives of the direction cosines [10]. The direction and derivative cosines are measured by 3-axis fluxgate magnetometer. The factors $\mathrm{k}_{\mathrm{i}}$ are connected with induced and constant magnetization of the ferromagnetic elements of the plane and with eddy currents. Every plane has some characteristic values of these factors. The digital compensator determines the factors $\mathrm{k}_{\mathrm{i}}$ on the basis of measurements of the magnetic flux density executed in the uniform magnetic field of the Earth with forced banking of the plane (pitch, yaw, roll). The simple magnetic system on a plane consists of a scalar magnetometer, a fluxgate magnetometer and a computer (fig.13).

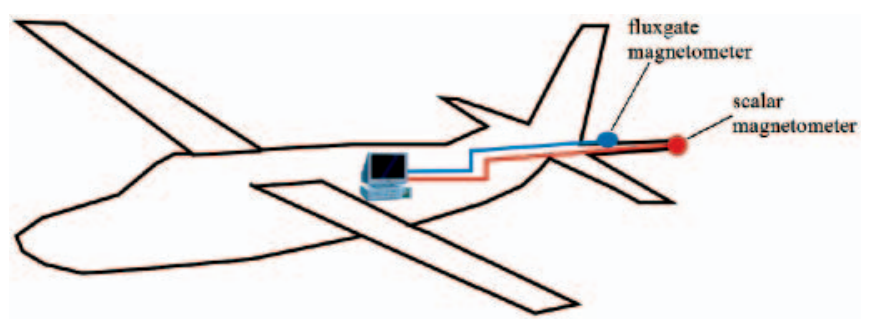

Fig. 13. The structure of the magnetic system on a plane

The example of the compensation of the magnetic disturbances of the plane was shown in fig.14. The magnetic system with a good compensator allows making measurements with sensitivity less than $100 \mathrm{pT}$.

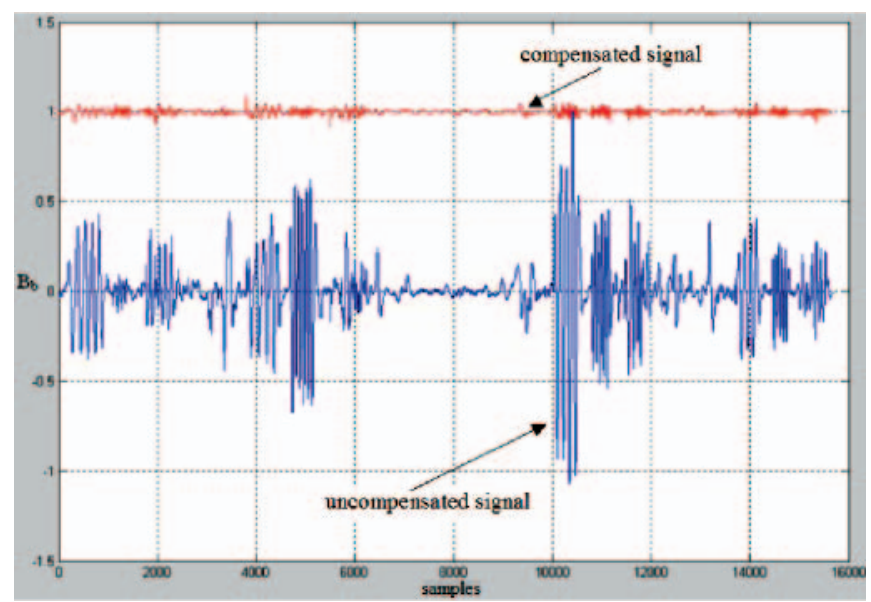

Fig. 14. The results of the compensation of the disturbances

$$
\text { of the magnetic field }
$$

The first Polish navy aircraft with magnetic system was shown in fig. 15.

This patrol-pathfinder navy plane An-28B1R Bis is used for instance in searching and tracking of submarines in the Baltic Sea.The systems installed on a helicopter do not need the 
compensator, if the magnetic sensor is in the remote distance from the helicopter. The magnetic sensor is mainly inside the gondola, which is towed by the helicopter (fig.16).

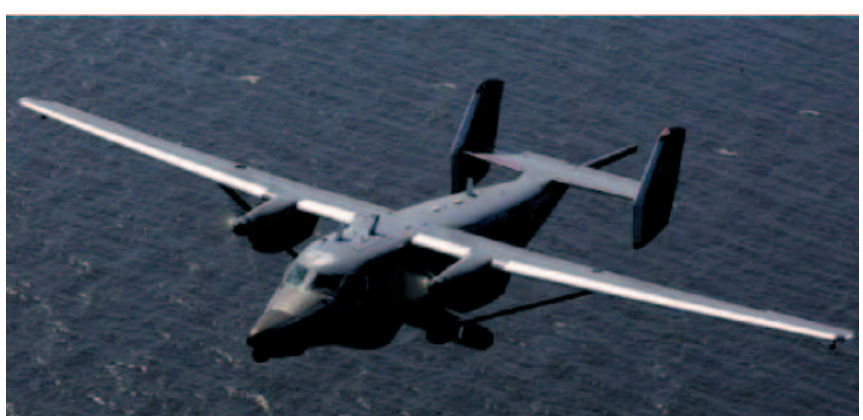

Fig. 15. The Polish navy aircraft with magnetic system (photo by: Mariusz Adamski)

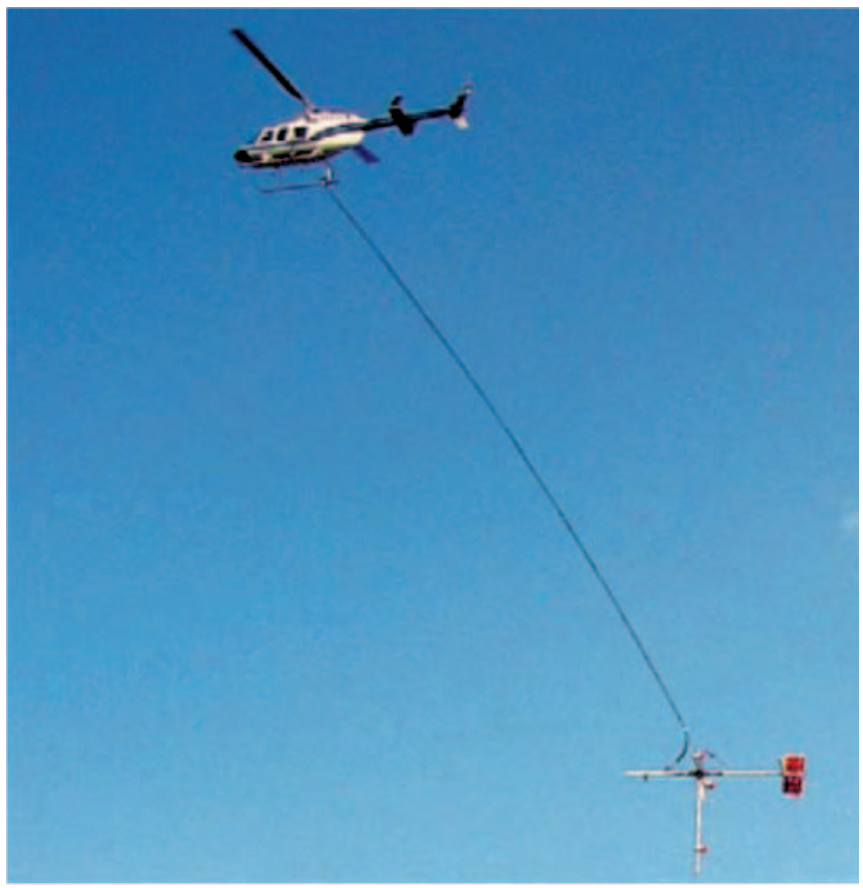

Fig. 16. The magnetic system on a helicopter with the magnetic sensor inside the gondola

The example of the Polish navy helicopter Mi-14Pł with magnetic system was shown in fig. 17.

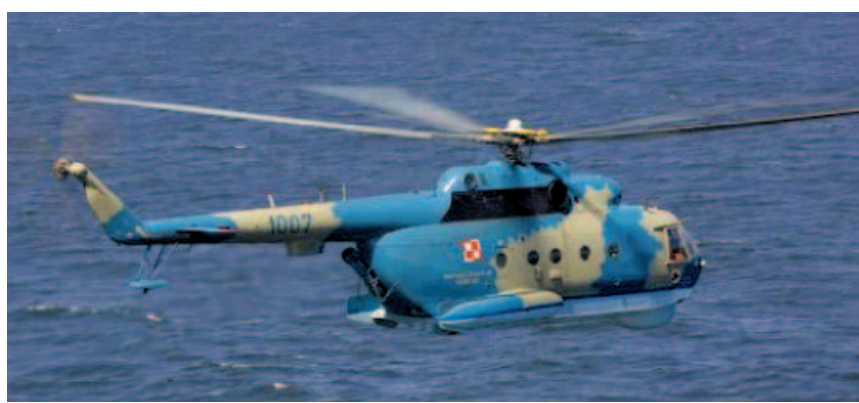

Fig. 17. The Polish navy helicopter Mi-14Pt with magnetic system (photo by: Mariusz Adamski)

\section{DETECTION OF OBJECTS IN LOCAL ANOMALY AREAS}

The magnetic systems installed on planes or helicopters are used in geological researches and submarines or wracks detection. The strong local magnetic anomalies cause serious problems in detection of small signals connected with ferromagnetic objects. A good example of a special area with strong local anomalies is the Baltic Sea. The magnetic system should have a sophisticated detection algorithm. Particular problems occur in the system of a helicopter towing a gondola. The trajectory of the gondola's flight is not a straight line. The deviations from the straight line of the gondola occur during the flight. The deviations are bigger during bad meteorological conditions (for example big crosswind). The gondola moves approximately along the trajectory:

$$
\begin{aligned}
& x(t)=v_{o} t \cos \left(\alpha_{k}\right)-A \sin \left(2 \pi f_{o} t\right) \sin \left(\alpha_{k}\right) \\
& y(t)=v_{o} t \sin \left(\alpha_{k}\right)+A \sin \left(2 \pi f_{o} t\right) \cos \left(\alpha_{k}\right)
\end{aligned}
$$

where:

$\mathrm{v}_{\mathrm{o}} \quad-$ a constant velocity of a platform

$\mathrm{A}_{\mathrm{y}}$ - amplitude of deviation

$\mathrm{f}_{\mathrm{o}}^{\mathrm{y}} \quad-$ frequency of deviation of the gondola

$\alpha_{k} \quad-$ an angle between direction of a straight line trajectory and $\mathrm{x}$ axis.

The frequency of the gondola's deviation depends on the length of the cable, mass and aerodynamics parameters of the gondola and meteorological conditions. The result of the gondola's deviation is the interference signal in measurements of the magnetic flux density. The example of the local magnetic anomalies similar to real anomalies on the Baltic Sea was presented in fig. 18 .

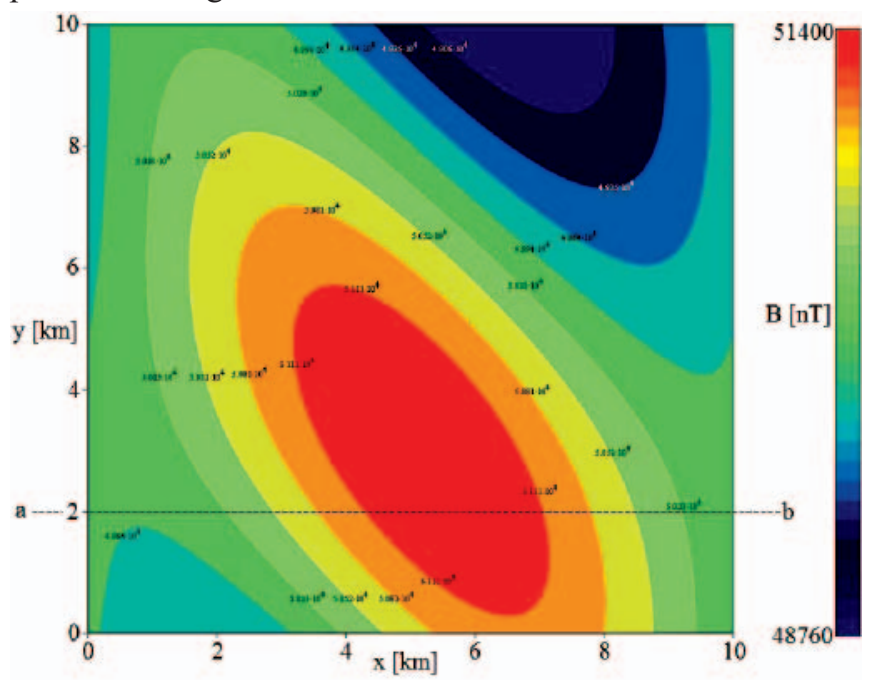

Fig. 18. The distribution of a local magnetic anomaly similar to real anomaly on the Baltic Sea

The interference signal $\Delta \mathrm{B}(\mathrm{t})$ appears in the measure signal with the frequency about $\mathrm{f}_{\mathrm{o}}$ (fig.19):

where:

$$
\Delta \mathrm{B}(\mathrm{t})=\mathrm{B}_{\mathrm{xyk}}(\mathrm{t})-\mathrm{B}_{\mathrm{xyp}}(\mathrm{t})
$$

$\mathrm{B}_{\mathrm{xyk}}(\mathrm{t})$ - the changes of the magnetic flux density in time along a non-linear trajectory

$\mathrm{B}_{\mathrm{xyp}}(\mathrm{t})$ - the changes of the magnetic flux density in time along a linear trajectory.

The amplitude and waveband of the interference signal depend on many factors such as:

* the distribution and values of the anomalies,

* the direction of the movements of the magnetic sensor,

* the mass of the gondola

* the length of the gondola's cable

* the meteorological conditions.

The values of these interferences could amount to several $\mathrm{nT}$ in extreme cases. 


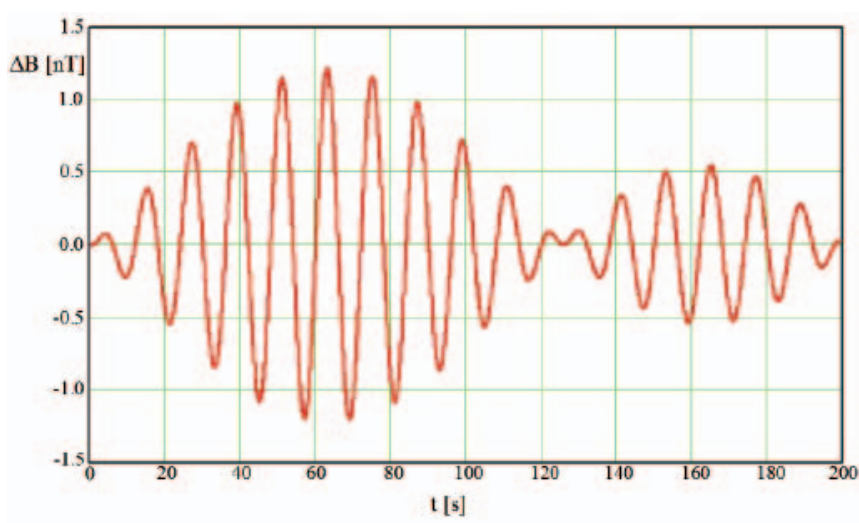

Fig. 19. The changes of the $\Delta B(t)$ caused by the gondola's deviation $\left(A=4 \mathrm{~m}, \alpha_{k}=0^{\circ}, v_{o}=50 \mathrm{~m} / \mathrm{s}, f_{o}=0.1 \mathrm{~Hz}\right)$ along a linear trajectory $a-b$ (fig. 18)

\section{CONLUSIONS}

The measure methods, which are used in geological researches, are presented in this paper. The special attention was paid to magnetic systems installed on mobile platforms. The magnetic field of the Earth obtained from mathematical model was compared to the real magnetic field in the selected part of the Baltic Sea. The results of the calculations showed that the mathematical model of the Earth's magnetic field does not consider local magnetic anomalies. The strong local magnetic anomalies cause serious problems with detection of underwater objects. Special problems appear in the magnetic system on a helicopter. The interference signals appear in the measurements of the magnetic flux density when the sensor is towed in the gondola. These signals have to be compensated in order to avoid false detection signals.

\section{BIBLIOGRAPHY}

1. Telford W.M., Geldart L.P., Sheriff R.E.: Applied Geophysics. Cambridge University Press, New York 1990
2. Www.canadianmigrogravity.com

3. Gabell A., Tuckett H., Olson D.: The GT-1A mobile gravity system. Abstract from the ASEG-PESA Airborne Gravity 2004 Workshop, pp.55-62, Sydney 2004

4. www.fugro.com

5. McFee J.E., Das Yogadhish, Ellingson R.O.: Locating and Identifying Compact Ferrous Objects. IEEE Transactions on Geoscience and Remote Sesnsing, vol.28,, no.2, pp.182-193, march 1990

6. MathCad 2000 User Guide, MathSoft Inc., 2000

7. Merrill R., McElhinny M., McFadden: The magnetic field of the Earth. International Geophysiscs Series. Volume 63. Academic Press. San Diego, California, USA, 1998

8. Ripka P.: Magnetic sensors and magnetometers. Artech House, Norwood 2001

9. Clem T.: Superconducting magnetic sensors operating from a moving platform. IEEE Trans. Appl. Supercond., Vol. 5(2), pp.2124-2148, 1995

10.Leliak P.: Identification and Evaluation of Magnetic Field Sources of Magnetic Airborne Detector Equipped Aircraft. IRE Trans. Aerospace and Navigational Electroncs, vol. 8, September 1961, pp. 95-105

11. Wołoszyn M.: Symulator kompensatora zaklóceń magnetycznych generowanych przez samolot. Pomiary Automatyka Kontrola, grudzień 2004

12.www.canadianmicrogravity.com

13.www.geometrics.com

14.www.fugro.com

CONTACT WITH THE AUTHOR

Mirosław Wołoszyn, Ph. D.

Gdansk University of Technology

Electrical and Control Engineering

G. Narutowicza 11/12

80-952 Gdańsk POLAND

email: mwolosz@ely.pg.gda.pl

phone: (+48) 583472435

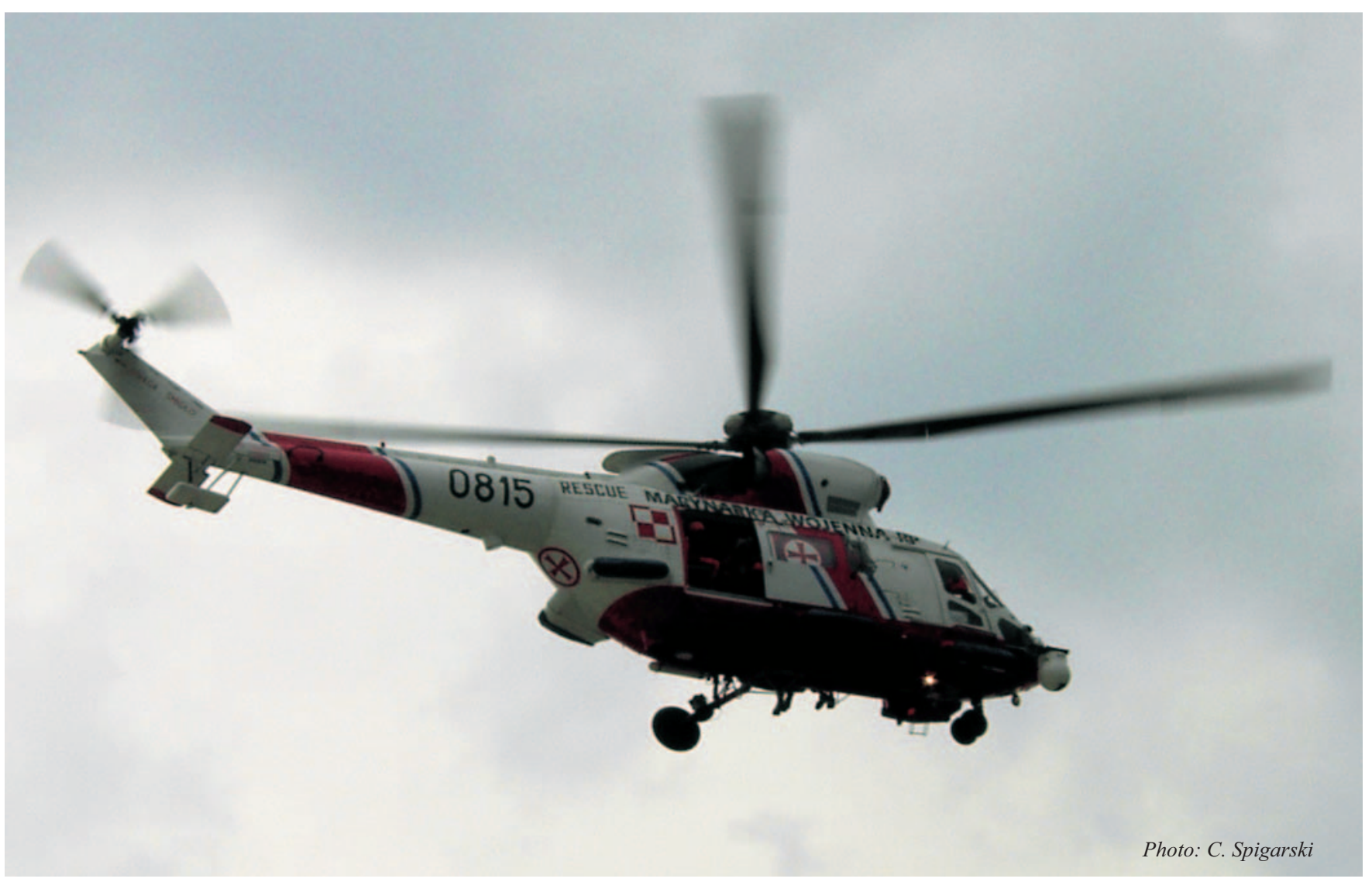

